\title{
A Social Profile Ontology to Enhance Learner Experience in MOOCs
}

\author{
https://doi.org/10.3991/ijet.v17i04.27389
}

\author{
Hajar Zankadi $\left.{ }^{1}{ }^{\bowtie}\right)$, Imane Hilal $^{2}$, Abdellah Idrissi $^{1}$, Najima Daoudi ${ }^{2}$ \\ ${ }^{1}$ Faculty of Sciences, Mohammed V University, Rabat, Morocco \\ ${ }^{2}$ Lyrica Labs, Information Science School (ESI), Rabat, Morocco \\ hajar_zankadi@um5.ac.ma
}

\begin{abstract}
Learners are more active and interactive in social media as they freely express themselves and share their thoughts and feeling which generates much useful information about their characteristics. However, the same learners are not usually interactive in MOOCs as much as they do in social media. Therefore, focusing on the Learner's social profile is a key component towards a successful and enriched experience of learning. Especially that MOOCs offer the possibility to sign up using social media accounts. Thereby, profile modelling is an essential step to capture the knowledge about the learners. In this paper, we aim to explore the information generated by the learner's participation in social media and combine it with his characteristics in MOOCs. Our approach is based on implementing an ontological learner profile that combines other ontologies (IMS-LIP standard, FOAF, and SIOC ontology) as well as some of the major concepts that describe a user in social media. The result of our solution is a social profile ontology (SPOnt) that describes the main concepts of a learner in each environment (MOOCs and social media). We rely on ontology mapping and merging techniques to maintain the semantic links between the different concepts of the two implemented ontologies.
\end{abstract}

Keywords-MOOCs, social media, ontology, user profile, METHONTOLOGY

\section{$1 \quad$ Introduction}

E-learning environments are incontestably recognized as an integral part of the learning process, as they provide significant contribution to its efficiencies and effectiveness. This is the case of MOOCs environments as they provide an open network for exchanging and sharing learning materials in a participatory atmosphere. They promote experiential learning spaces that collapse time zones and national boundaries [1]. However, many learners do not have a successful learning experience as there is little support for social activities which may leads to their drop-out [2]. A recent research study [3] has pointed out the factors that affect learners' retention and the results have identified that learner's: (i) self-discipline, (ii) quality of faculty, (iii) interaction and (iv) institutional support are of prime importance. 
Moreover, positive learner experience is related to social presence as stated in [4]. Social presence is largely correlated positively with satisfaction and perceived learning. Therefore, MOOCs need to provide relevant mechanisms to encourage interaction for driving learners' continuous participation [5]. Thus, they should be designed to meet learners' cognitive requirements and respond to their preferences and satisfaction.

In a previous work [6], we proposed a social course design using UML diagrams mainly: Use Case and Sequence diagrams to describe the different scenarios occurring when using it. We created two use cases for the different key roles in e-learning environments. We categorized them into frontend and backend user. The first category, includes: Authenticated user, learner and guest. While the second one contains the course creator and the tutor. The different actions included in the model are: "like/ dislike action", "Comment action", and "Share action". The model also calculates the score of each action to be displayed to the learners and serve as feedback for the future learners. The aim of this work, is to offer a suitable model for interactivity and sociability to encourage learners participate and collaborate with each another.

Several studies have reported positive affordances of social media for teaching and learning. According to [7], social media emphasized the potential to increase interaction and networking between teachers and learners in the light of the advocated constructivist approaches. Which means that learning occurs as learners are actively involved in a process of knowledge construction, rather than passively receiving information [8]. Thus, social media are considered a powerful driver of change for teaching and learning practices, in terms of openness, interactivity and sociability [9]. They are seen as an emerging interactive learning tool and have a unique advantage in connecting learners in virtual community.

In another work [10], we investigated the main challenges of both MOOCs and social media, in particular, Facebook, using SWOT analysis. We found out that MOOCs' strengths lie on their open access to course materials with free fees and this encourages a wide range of learners to enroll them. Thanks to the pedagogy experience and the richness of the content they deliver to their learners, MOOCs are becoming mature platforms. Consequently, collaboration is increased and MOOCs are considered an accelerator for online learning. Although the massive registration, learners suffer from a low level of interaction which make them feel isolated and consequently the risk of drop-out becomes highly presented.

On the other hand, Facebook is designed as an attractive space to potential new users anytime and anywhere. The addiction to the service maintains a reliable social interaction between its users. This strength fosters more the use of Facebook in a way that makes its users more engaged to stay connected to each other unlike MOOCs. We concluded that MOOCs and social media need to complete each other.

MOOCs and social media are different from the point of view of users' interactions. This diversity is important as interaction is highly stronger in social media. For this purpose, we aim to exploit it in order to foster more MOOCs' interaction using ontologies.

Ontologies are used to identify and to solve the heterogeneity problems. Generally, they are used at schematic level as a way to set an explicit formal vocabulary for sharing knowledge[11]. They are formal specifications of concepts in a domain of interest. 
Their classes, relationships, constraints and axioms define a common vocabulary to share knowledge [12]. Additionally, ontologies have proved a successful experience for representing knowledge about the learner profile and ensure the semantic between its elements.

Our approach consists of exploiting the learner 's behavior, interaction and personal involvement in social media for the purpose of improving his participation vis-à-vis the courses he enrolls in MOOCs.

In this paper, we propose an ontology-based user profile that describes the main concepts and sub-concepts of a learner in each environment (MOOCs and social media). We re-used existing ontologies and standards such as IMS-LIP standard, FOAF, SIOC ontology, etc. as well as some of the major concepts that describe a user in social media. We rely on ontology mapping and merging techniques to maintain the semantic links between the different concepts of the two implemented ontologies. The final result of our approach is the social profile ontology (SPOnt) that contains social information about the learner such as interests and preferences that plays in important role to recommend the suitable course to his needs.

The remainder sections of this paper are organized as follows: section 2 highlights the related work. Section 3 describes the proposed solution while section 4 points out the conclusion and future work. Writing a new document with this template.

\section{Related work}

Learner Profile represents an important source of information that not only contains basic information such as the name, age, and gender of learners, but also reveals the learning ability, preferences, and condition of the learners [13].

Several research works propose the building of the learner profile in different areas. An ontology-based learner profile [14] is developed using Knowledge Engineering Methodology. The ontology combines the pedagogical and psychological characteristics of the learner as well as the health risks generated by the COVID 19 epidemic. The ontology contains three main classes, the first one capturing academic information compliant with the IMS-LIP standard. The second collects information related to the mental disorders that the learner may have (anxiety, depression, PTSD) and their respective degrees of severity. The last one is related to Covid-19, it gathers the necessary information on the state of health of the learner if he is contaminated or at risk of contracting the virus. Authors in [15] propose an ontological learner model for adaptive e-learning environments. They used IMS-LIP, IMSACCLIP and IMS-RDCEO standards and incorporated their characteristics to the proposed learner. In another work [16], a learner model based on XAPI statements is built. It combines the formal and informal tools to enrich the learner profile and ensure interoperability between systems. The authors present also a tool to transform the collected data into XML model based on the IMS-LIP standard.

In the context of gamified learning systems, authors in [17] proposes an approach to represent the learner's model and classify its profile in an adaptive gamified learning system. They develop a student profile ontology "SPOnto" that classifies learners into 
different types with the help of classification models such as Logistic Regression, Support Vector, Multinomial Naive Bayes, XGBoost, and CNN-LSTM. The aim of the work is to improve the motivation and the engagement of students within the system and enhance the quality of education and learning outcomes. Similarly, the work presented in [18], propose an adaptive gamification domain knowledge ontology "AGELearn $\uparrow$ '. It contains the learner's aspects such as personalities, needs, values and motivation combined with his experience in a gamified learning system. The AGE-Learn $\dagger$ ontology is evaluated using the Criteria-based evaluation approach which includes: clarity, consistency, conciseness and correctness.

For the purpose of content recommendation, authors in [19], developed a learner profile ontology and a learning content ontology following the model proposed by Felder Silverman (FSLSM). Each learning material is mapped to a specific learning style based on the FSLSM. The learners' learning styles is detected automatically using a machine learning-based approach. The learning style is used as a common data-type property to match the two ontologies and generate personalized recommendations. In another work, authors in [20], proposed an ontological approach for the representation of learner profile and learning styles for the aim of personalized E-learning. The ontological representation of learners' profiles and learning styles gives a detailed description about them which allows the delivery of the pertinent content for each learner according to his preferences and characteristics.

The work presented in [21], represent the interaction process between user profile and its context for collaborative learning using ontology. The approach analyzes the role assignments, permissions, restrictions and the definition of rules that are applied to the user. Authors in [22], propose an ontology to classify learner profile based on their activities and personal information. The ontology can be used to provide learning materials based on the learner activities in adaptive E-Learning system.

Many works have focused on the enrichment of the learner profile while others have been concentrating on modeling the learner profile.

The work highlighted in [23], consisted on an RDF Schema (RDFS) based model that generate automatically semantic user profiles for authors of scholarly literature. The presented approach analyzes full-text research articles through various natural language processing (NLP) techniques. The objective is to help scholarly applications understand their users' interests, tasks, and 5 competences, by incorporating these user profiles in their design. Moreover, authors in [24], pointed out a user profile for the open educational resources (OER) recommendation. The user profile takes into consideration: i) the constraints and opportunities that an open learning environment could offer in real time to obtain users information; ii) the general characteristics that identify a OER user; and iii) the particular characteristics that can make it possible to differentiate one group of users from other. In other work, authors in [25], describes an ontology network-based student model for Multiple Learning Environments (ON-SMMILE). The new semantic web-based model combines information related to (i) students and their knowledge state, (ii) assessments that rely on rubrics and different types of objectives, (iii) units of learning and (iv) information resources previously employed as support for the student model, in intelligent virtual environment for training/instruction. 
Ontologies were widely used in e-learning to model learner profile. For the case of social media, there has not been much work done to model the user profile.

Authors in [26] developed an ontological user model called OUPIP (Ontology-Based User Profile for Impairment Person). The ontology extends existing ontologies that adapts applications and devices according to the user's profile, disability and dynamic context. The approach has been applied in a typical real-life scenario in which personalized services are provided to impairment person through a mobile phone. In another work [27], authors introduced a scalable and automated technique to model the user profile. The proposed model obtains automatically the interests and intentions of users through the URLs they share.

Many works have focused on enriching or modeling the learner profile based on his interaction, activities and personal information in e-learning environment for different purposes. To the best of our knowledge, there has not been much work in the area of modeling and enriching the learner profile based on his characteristics, activities and interaction in social media.

Our proposed solution consists on gathering information about the learner in social media including his preferences, interest, activities and personal involvement in order to enrich his profile in MOOCs. The purpose is to foster more his interaction in MOOCs. The following section will focus in details on our proposed solution.

\section{$3 \quad$ Proposed approach}

\subsection{Overall architecture}

Figure 1 depicts the overall architecture of our proposed solution. It consists of:

- Generating a learner profile in MOOCs using ontology.

- Generating a user profile in social media using ontology.

- Relying on ontology mapping and merging techniques to generate the learner social profile. 


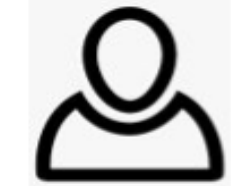

Learner in MOOCs

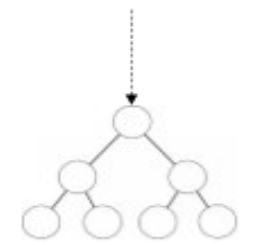

Learner Profile

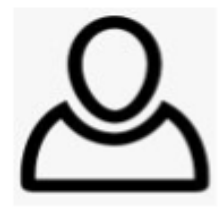

User in Social Media

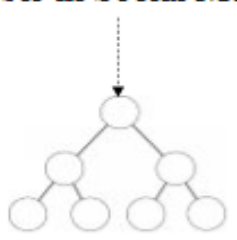

User Profile

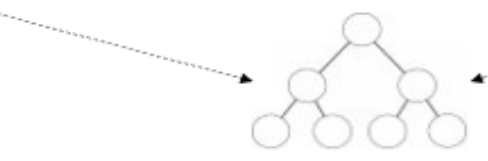

Social Profile

Fig. 1. Overall architecture

\subsection{The proposed solution}

Our proposed solution is based on many standards and ontologies. Figure 2 highlights our proposed architecture in more details.

The generated ontology is a global ontology that will contain knowledge about learner in both environments (MOOCs and social media) based on his activities and interaction in social media which will encourage more interaction in MOOC. 


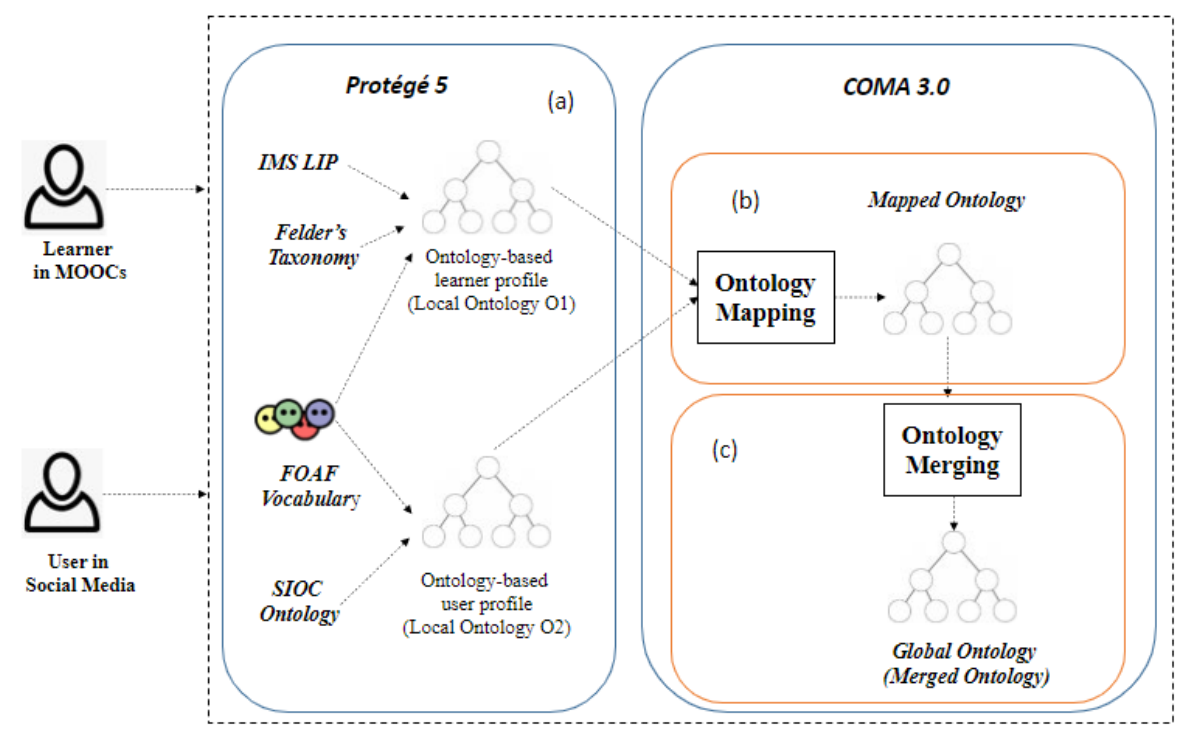

Fig. 2. Detailed architecture of the proposed solution

The proposed architecture is articulated about three main components:

1. Component (a): Highlights the creation of the two local ontologies using Protégé 5 [28]:

a) Local ontology O1: Describes the learner profile in MOOCs. We reuse: IML LIP standard [29], FOAF vocabulary [30] and Felder-Silverman taxonomy [31] which is a four-dimensional model:

- Perceive Dimension ("Sensing" / "Intuitive"): Describes how the learners prefer to perceive or take in information.

- Process Dimension ("Active" / "Reflective"): Describes how the learners prefer to process information.

- Receive Dimension ("Visual" / "Verbal"): Describes how the learners prefer information to be presented.

- Understand Dimension ("Sequential" / "Global"): Describes how the learners prefer to organize and progress toward understanding information.

b) Local ontology O2: Describes the user profile in social media. We reuse FOAF standard and SIOC ontology [32]. We add as well the elements that constitutes user's personal involvement and interaction in social media.

2. Component (b): Describes the ontology mapping process of the two local ontologies: mapping $(\mathrm{O} 1, \mathrm{O} 2)$. It provides semantic correspondences between similar elements in different ontologies [33]. It is a specification of consistence about concepts and relations. 
For this purpose, we use COMA 3.0 that performs matching and merging on XSD (XML Schema), OWL (OWL-Lite), XDR (XML Data Reduced) and relational database schemas [34].

3. Component (c): Describes the ontology merging process: the input is the mapped ontologies and the output is a global ontology that contains our social profile. Ontology merging is the process of a new ontology creation, which is the union of the source ontologies. The original ontologies have similar or overlapping domains but they are unique and not revisions of the same ontology [35].

The following section will present in more details the sequence of steps of our solution, as described in Figure 2.

\subsection{Implementation of the proposed solution}

The implementation of the solution is organized in three major steps as presented in Figure 3.

$$
\begin{array}{|c|c}
\text { Step 1: } \\
\begin{array}{c}
\text { Ontology } \\
\text { Ontology } \\
\text { creation using } \\
\text { Methontology }
\end{array} \\
\text { mapping using } \\
\text { COMA } 3.0
\end{array} \Rightarrow \begin{gathered}
\text { Step 3: } \\
\text { Ontology } \\
\text { merging using } \\
\text { COMA } 3.0
\end{gathered}
$$

Fig. 3. Sequence of steps for the implementation of the social profile ontology

Step 1: Ontology creation process. The methodological approach that is followed to develop, implement and represent the ontology in our work is guided by METHONTOLOGY, one of the most popular and comprehensive methodologies for ontology development.

METHONTOLOGY is defined as a well-structured methodology including a set of activities, techniques to carry out each one, and deliverables to be produced after the execution of such activities using its attached techniques [36].

a) Ontology specification: This phase aims to produce the ontology requirements specification document (ORSD). The document covers the ontology's primary objective, purpose, granularity level, and scope [37]. After a literature review of ontology- based user profile in the area of e-learning, we determined its ORSD, as presented in Table 1. 
Table 1. Ontology requirements specification document (ORSD)

\begin{tabular}{|c|l|}
\hline Domain & E-learning, MOOCs and social media \\
\hline Purpose & $\begin{array}{l}\text { Build a social learner profile that contains information about leaners from his } \\
\text { interaction and participation in both MOOCs and social media }\end{array}$ \\
\hline Scope & Formal \\
\hline $\begin{array}{c}\text { Requirements } \\
\text { and }\end{array}$ & $\begin{array}{l}\text { List of the different concepts that model the user profile in both MOOCs and } \\
\text { social media environments, including the preferences of the user, personal } \\
\text { involvement including behavior vis-à-vis a post (like, comment, share), } \\
\text { learning styles, etc. }\end{array}$ \\
\hline $\begin{array}{c}\text { competency questions } \\
\text { Which characteristics describe a learner in MOOCs and social media? } \\
\text { Which characteristics are important to improve learner interaction in } \\
\text { MOOCs? } \\
\text { Requirements are analyzed based on study cases about the challenges that } \\
\text { surround learners in their process of learning including drop-out, lack of sat- } \\
\text { isfaction, lack of interaction. }\end{array}$ \\
\hline
\end{tabular}

b) Knowledge acquisition: The objective of this phase is to gather and elicit the domain knowledge that is required for developing the ontology [38]. During specification until conceptualization, our solution collects knowledge for modelling ontology using literature review approach about learner in MOOCs. Moreover, knowledge about user profile has been acquired from other sources of information including: articles, well known standards, handbooks, and other existing ontologies. We start by modeling the main classes of each ontology, defining the concepts, relationships and also attributes.

c) Conceptualization: The aim of this phase is to structure the domain knowledge in a conceptual model that describes the problem and its solution in terms of the domain vocabulary identified in the ontology specification [38]. The conceptualization activity includes the set of structuring knowledge tasks, shown in Figure 4 [39]. 


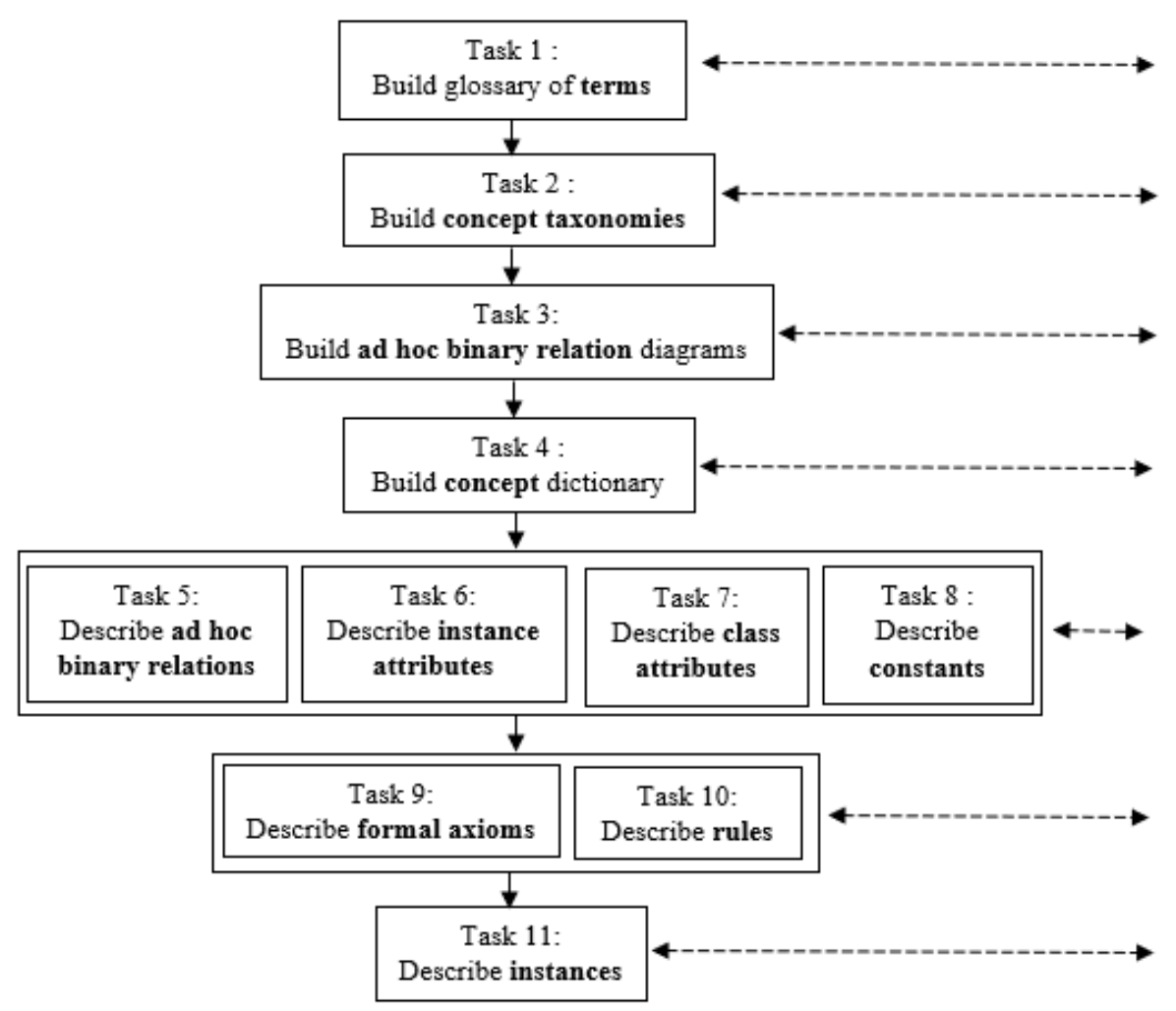

Fig. 4. knowledge structure of conceptualization phase

Task 1: Glossary of terms. Table 2 and Table 3, highlight an excerpt of terms used to construct the two ontologies.

Table 2. An excerpt of the glossary of terms of ontology-based learner profile

\begin{tabular}{|c|c|c|c|}
\hline Name & Synonyms & Description & Type \\
\hline $\begin{array}{l}\text { Learner } \\
\text { Profile }\end{array}$ & Profile & Describes learner's characteristics and information & Concept \\
\hline Identification & $\begin{array}{l}\text { Basic Information/ } \\
\text { Personal } \\
\text { Information }\end{array}$ & $\begin{array}{l}\text { Personal information such as name, address contact } \\
\text { info, agent and demographics. }\end{array}$ & Concept \\
\hline Online Account & User account & $\begin{array}{l}\text { Describes the different Online account the learner } \\
\text { has, such as "Gmail account", "Facebook account", } \\
\text { "LinkedIn account", etc. }\end{array}$ & Concept \\
\hline Learning Preferences & -- & $\begin{array}{l}\text { Describes the learner preferred way for learning in- } \\
\text { cluding: preferred learning materials, preferred } \\
\text { learning styles, languages, etc. }\end{array}$ & Concept \\
\hline Has Profile & -- & $\begin{array}{ll}+2 & - \\
\end{array}$ & Relation \\
\hline Has Account & - & $-{ }_{-1}$ & Relation \\
\hline Account & -- & Describes the name of the online account & attribute \\
\hline
\end{tabular}


Paper-A Social Profile Ontology to Enhance Learner Experience in MOOCs

\begin{tabular}{|l|c|c|c|}
\hline Name & & & \\
\hline-- & -- & -- & -- \\
\hline
\end{tabular}

Table 3. An excerpt of the glossary of terms of ontology-based user profile

\begin{tabular}{|l|c|c|c|}
\hline \multicolumn{1}{|c|}{ Name } & Synonyms & Description & Type \\
\hline Personal Involvement & -- & $\begin{array}{c}\text { Relates to user's personal connection and interaction in } \\
\text { terms of the relationship and information exchange. } \\
\text { e.g.,"Posts", "Hashtag", etc. }\end{array}$ & Concept \\
\hline Interaction & -- & $\begin{array}{c}\text { Describes the user interaction, including liking, com- } \\
\text { menting, posting, etc. }\end{array}$ & Concept \\
\hline Group & User group & $\begin{array}{c}\text { A set of User Accounts whose owners have a common } \\
\text { purpose or interest. Can be used for access control pur- } \\
\text { poses. }\end{array}$ & Concept \\
\hline Relationship & Friends & The user's relation with others. & Concept \\
\hline Knows & Has relation & -- & Relation \\
\hline Interact by & -- & -- & Relation \\
\hline Group Name & -- & -- & Attribute \\
\hline-- & -- & -- \\
\hline
\end{tabular}

Task 2 \&3: Concept Taxonomies and Ad hoc binary relations diagram. METHONTOLOGY proposes to use the four taxonomic relations defined in the Frame Ontology [40] and the OKBC Ontology [41]: Subclass Of, Disjoint-Decomposition, Exhaustive-Decomposition, and Partition. The goal of Ad hoc binary relations diagram is to establish ad hoc relationships between concepts of the same (or different) concept taxonomy [39]. Figure 5 and Figure 6 present a fragment of the ad hoc binary relation diagram of the two ontologies.

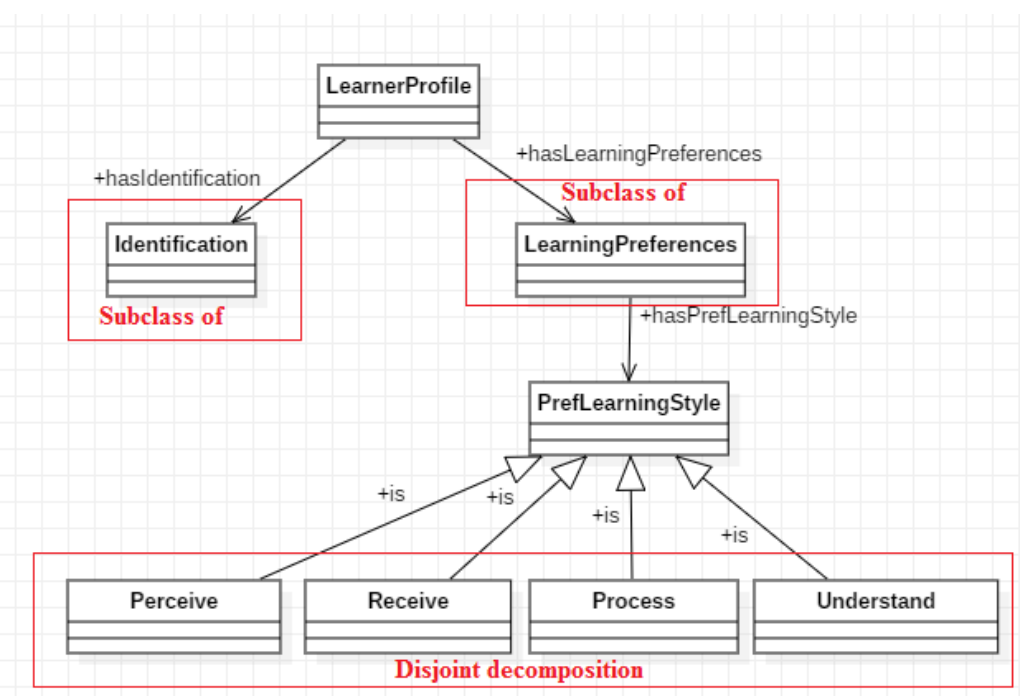

Fig. 5. ad hoc binary relation diagram of learner profile ontology 


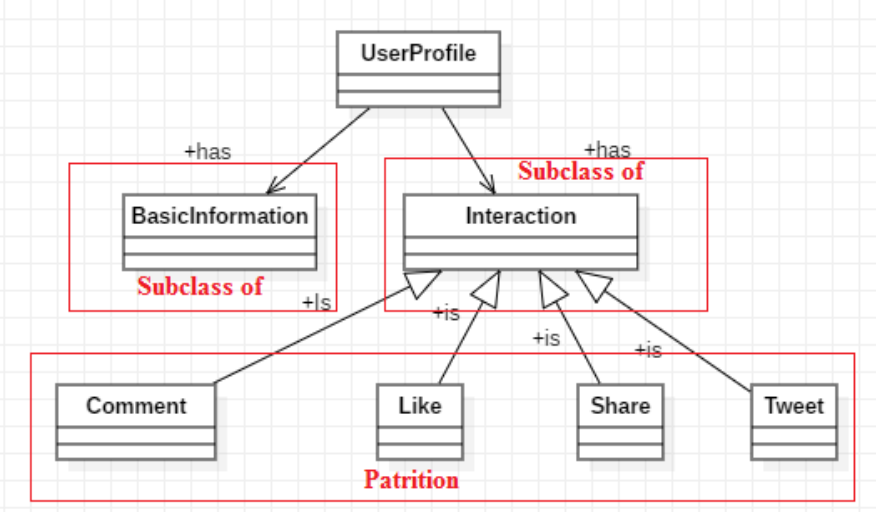

Fig. 6. ad hoc binary relation diagram of user profile ontology

Task 4: Concept dictionary. A concept dictionary contains all the domain concepts, their relations, their instances, and their class and instance attributes [39], as highlighted in Table 4 and Table 5.

Table 4. An excerpt of the concept dictionary of ontology-based learner profile

\begin{tabular}{|l|c|c|c|c|}
\hline \multicolumn{1}{|c|}{ Concept Name } & Instance & $\begin{array}{c}\text { Class } \\
\text { Attribute }\end{array}$ & $\begin{array}{c}\text { Instance } \\
\text { Attribute }\end{array}$ & Relations \\
\hline $\begin{array}{l}\text { Learner } \\
\text { Profile }\end{array}$ & -- & -- & -- & $\begin{array}{c}\text { Has Identification } \\
\text { Achieves Degree } \\
\text { Has Internet } \\
\text { Has learning preferences } \\
\text { Has activity } \\
\text { Holds account }\end{array}$ \\
\hline Online & & -- & $\begin{array}{c}\text { Account Name } \\
\text { Account URL }\end{array}$ & \\
Account & $\begin{array}{c}\text { Coursera } \\
\text { EdX } \\
\text { Udemy } \\
\text { Facebook } \\
\text { Gmail }\end{array}$ & -- & $\begin{array}{c}\text { Competency name } \\
\text { Competency de- } \\
\text { scription }\end{array}$ & Has competency \\
\hline Competency & - & -- & $\begin{array}{c}\text { Learning } \\
\text { material type } \\
\text { Learning } \\
\text { material format }\end{array}$ & PrefLearningMaterial \\
\hline Learning materials & $\begin{array}{c}\text { Videos } \\
\text { Images } \\
\text { etc }\end{array}$ & -- & -- & -- \\
\hline- & -- & - & & \\
\hline
\end{tabular}


Table 5. An excerpt of the concept dictionary of ontology-based learner profile

\begin{tabular}{|c|c|c|c|c|}
\hline Concept Name & Instance & $\begin{array}{c}\text { Class } \\
\text { Attribute }\end{array}$ & $\begin{array}{l}\text { Instance } \\
\text { Attribute }\end{array}$ & Relations \\
\hline User Profile & -- & -- & -- & $\begin{array}{c}\text { Follows } \\
\text { has BasicInformation } \\
\text { hasPersonalInvolvement } \\
\text { has Interest } \\
\text { has Preferences } \\
\text { Holds Account } \\
\text { Interact_by } \\
\text { Knows }\end{array}$ \\
\hline $\begin{array}{l}\text { User } \\
\text { Account }\end{array}$ & $\begin{array}{l}\text { Facebook } \\
\text { Gmail } \\
\text { Instagram } \\
\text { LinkedIn } \\
\text { Tweeter }\end{array}$ & -- & $\begin{array}{l}\text { Account name } \\
\text { Account URL }\end{array}$ & $\begin{array}{l}\text { Follows } \\
\text { Member_of }\end{array}$ \\
\hline Post & -- & -- & $\begin{array}{c}\text { Creator } \\
\text { Description }\end{array}$ & $\begin{array}{l}\text { Has reply } \\
\text { shared_by }\end{array}$ \\
\hline Group & -- & -- & $\begin{array}{c}\text { Group_name } \\
\text { Group_description } \\
\text { moderator_name }\end{array}$ & $\begin{array}{l}\text { Has member } \\
\text { Has moderator }\end{array}$ \\
\hline-- & -- & -- & -- & -- \\
\hline
\end{tabular}

Task 5: ad hoc binary relation in details. The goal of this task is to describe in detail all the ad hoc binary relations included in the concept dictionary, and to produce the ad hoc binary relation table. Tables 6 and 7 highlight an excerpt of ad hoc binary relation for the two ontologies.

Table 6. An excerpt of ad hoc binary relation for ontology-based learner profile

\begin{tabular}{|l|c|c|c|c|}
\hline \multicolumn{1}{|c|}{ Relation Name } & Source Concept & $\begin{array}{c}\text { Source Cardinality } \\
\text { (Max) }\end{array}$ & Target Concept & Inverse Relation \\
\hline Has Identification & Learner Profile & 1 & Identification & -- \\
\hline Has learning preferences & Learner profile & N & Learning Preferences & -- \\
\hline Has Learning Styles & Learner Profile & N & Learning Styles & -- \\
\hline-- & -- & -- & -- & -- \\
\hline
\end{tabular}

Table 7. An excerpt of ad hoc binary relation for ontology-based user profile

\begin{tabular}{|l|c|c|c|c|}
\hline \multicolumn{1}{|c|}{ Relation Name } & Source Concept & $\begin{array}{c}\text { Source Cardinality } \\
\text { (Max) }\end{array}$ & Target Concept & Inverse Relation \\
\hline Has Basic Information & User Profile & 1 & Basic Information & -- \\
\hline Interact by & User profile & $\mathrm{N}$ & Interaction & -- \\
\hline Includes & Interaction & $\mathrm{N}$ & Like & -- \\
\hline-- & -- & -- & -- & -- \\
\hline
\end{tabular}


Task 6: instance attributes in details. The aim of this task is to describe in detail all the instance attributes already included in the concept dictionary by means of an instance attribute table. Tables 8 and 9 highlight an excerpt of instance attributes for both ontologies.

Table 8. An excerpt of instance attributes for ontology-based learner profile

\begin{tabular}{|l|c|c|c|c|}
\hline Instance Attribute Name & $\begin{array}{c}\text { Concept } \\
\text { Name }\end{array}$ & $\begin{array}{c}\text { Value } \\
\text { Type }\end{array}$ & Value Range & Cardinality \\
\hline Name & Identification & String & -- & $(1,1)$ \\
\hline Gender & Identification & String & -- & $(1,1)$ \\
\hline Learning Style Type & Learning Style & String & -- & $(1,1)$ \\
\hline-- & -- & -- & -- & -- \\
\hline
\end{tabular}

Table 9. An excerpt of instance attributes for ontology-based user profile

\begin{tabular}{|l|c|c|c|c|}
\hline Instance Attribute Name & $\begin{array}{c}\text { Concept } \\
\text { Name }\end{array}$ & $\begin{array}{c}\text { Value } \\
\text { Type }\end{array}$ & $\begin{array}{c}\text { Value } \\
\text { Range }\end{array}$ & Cardinality \\
\hline Number Likes & Like & Integer & -- & $(1,1)$ \\
\hline Last reply date & Comment & Literal & -- & $(1,1)$ \\
\hline Account name & Online Account & String & -- & $(1,1)$ \\
\hline-- & -- & -- & -- & -- \\
\hline
\end{tabular}

Tasks 7,8,9,10 \&11: Describe class attributes, constants, formal axioms, rules and instances. The aim of those tasks is to describe in details all the class attributes, constants, formal axioms and rules already included in the concept dictionary. Once the conceptual model of the ontology has been created, it is important to define relevant instances that appear in the concept dictionary inside an instance table [39].

d) Integration: we use well known standards for modeling the learner profile in MOOCs including: FOAF, IMS LIP standard as well as Felder's taxonomy for describing the learning styles. For representing the user profile in social media, we use the SIOC ontology.

e) Implementation: we use Protégé v5 to implement the two local ontologies. Figure 7 and Figure 8 represent the implemented ontologies. 
Paper-A Social Profile Ontology to Enhance Learner Experience in MOOCs

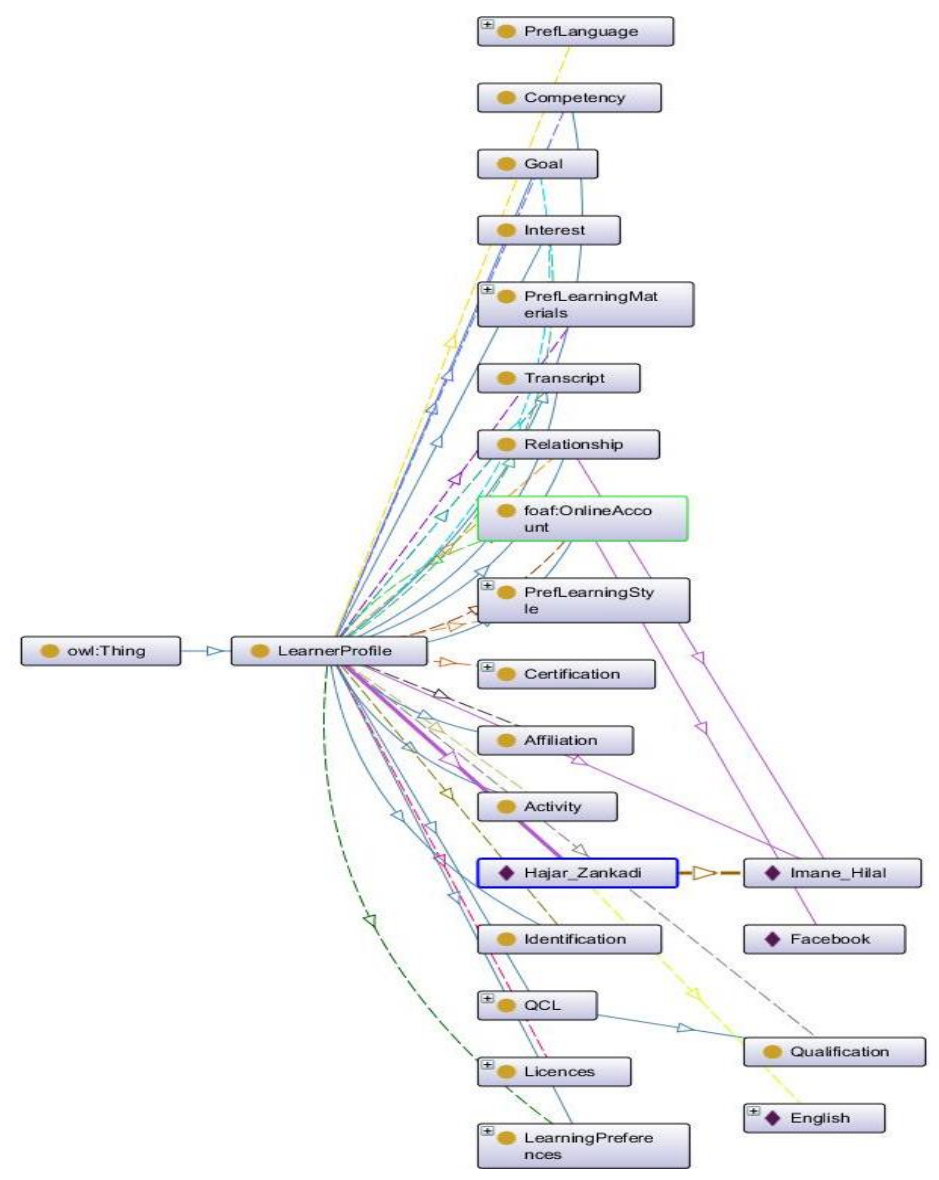

Fig. 7. Graphical representation of learner profile ontology 


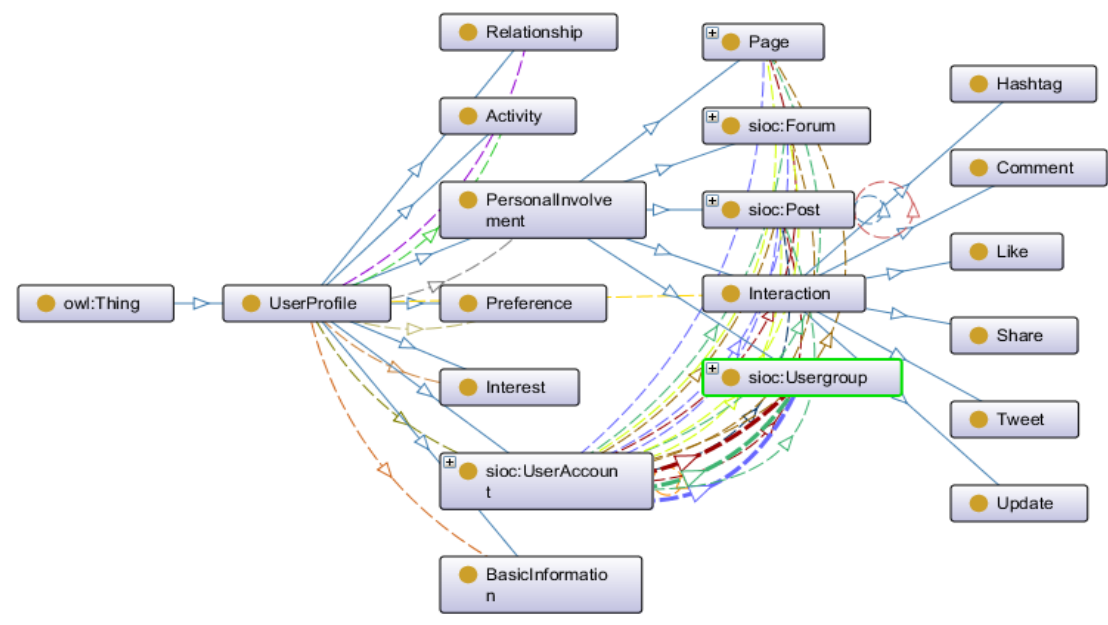

Fig. 8. Graphical representation of user profile ontology

f) Evaluation: we have selected the Criteria-based evaluation approach. This approach serves to test the usability of SPOnt. The criteria-based evaluation includes the refinement of our implemented ontology according to the domain experts' feedback. These criteria are:

- Clarity: we follow Gruber's requirements [42]. In our case, we rely on the feedbacks of the interviewed domain experts in e-learning to refine and verify the clarity of the ontology. For example, at the level of the local ontology that represents the user profile in social media, we had "interaction" and "Personal Involvement" as two different concepts. The concept "Interaction" is used to represent user actions in terms of "liking/disliking", "commenting/replying", "sharing a post" while the concept "Personal Involvement" points out other actions including also his interaction. During the interview, experts prefer to consider "Interaction" as a sub-concept of "Personal Involvement" to deliver a more intended meaning.

- Consistency/coherence: Based on experts' advice, the consistency check produced many examples where changes were proposed. Ontology concepts should have a logical consistency and avoid contradictions or ambiguity. We use Pellet reasoner for that purpose.

- Conciseness: According to Gómez-Pérez [43], “ontology is concise if it doesn't include unnecessary or useless definitions besides explicit redundancies between definitions". For example, learner ontology had 2 main classes "Learner" and "learner Profile". The first represents the learner's personal information, degrees and relationships while the second one describes the profile such as learning style, preferred learning materials, etc. We realized that having the class "learner" is unnecessary, we added its sub-classes to the "learner profile" class.

- Correctness: "It is the correspondence of real-world entities and properties with ontology concepts and properties". We have carefully considered this criterion in 
our ontology development and validation. Domain experts' feedback has greatly assisted in the correctness and the verification of the ontology.

Step 2: Ontology mapping process using COMA 3.0. In order to find similarities between the entities of the implemented ontologies, we use COMA 3.0 which is a matching algorithm tool for ontology mapping. COMA implements an iterative algorithm based on a collection of matching algorithms (matchers) [44].

We applied three individual matchers: "AllContextW", "NodesPathW" and "NodesNamesW". Figure 9 represents an overall architecture of the mapping process. We choose to highlight the mapping between Relationship concepts in both ontologies. Figures 10,11 and 12 below point-out the match result for each matcher: Each line represents a correspondence between two concepts.

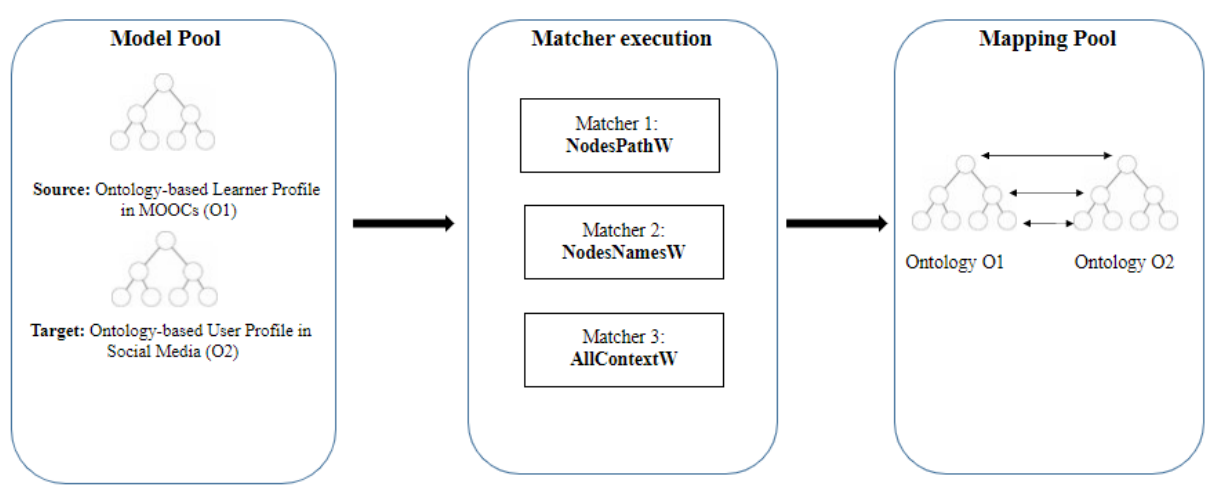

Fig. 9. Overall architecture of the mapping process

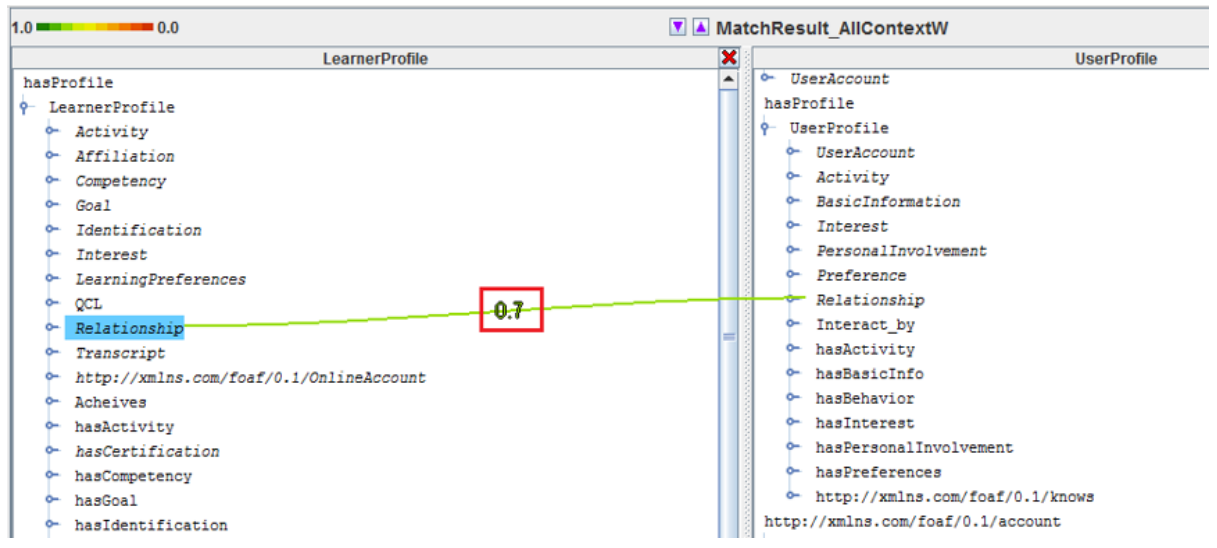

Fig. 10.Match result using AllContextW matcher 


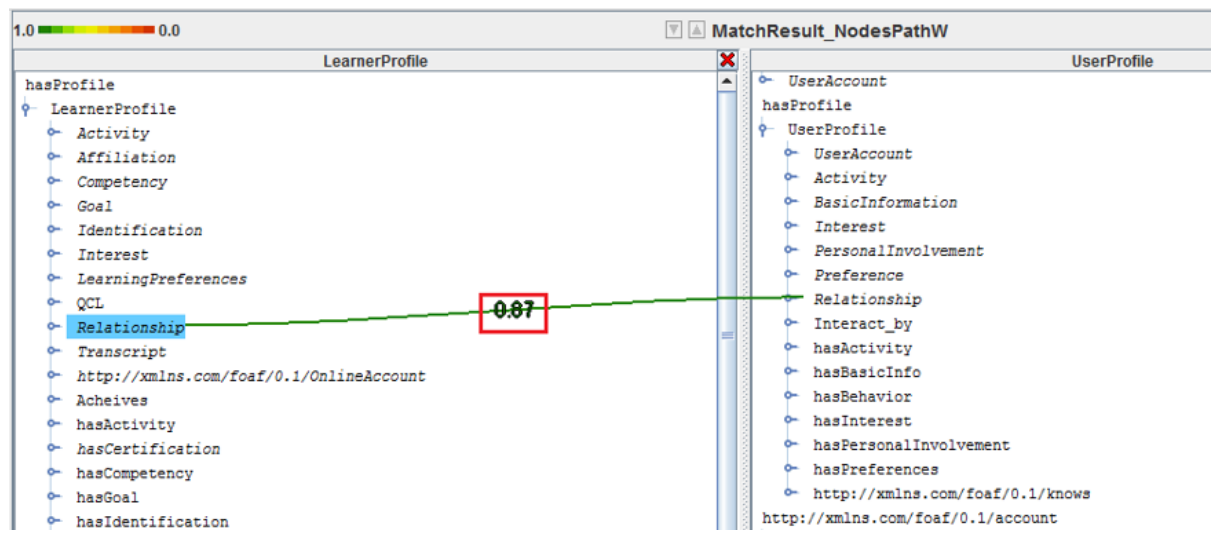

Fig. 11.Match result using NodesNameW matcher

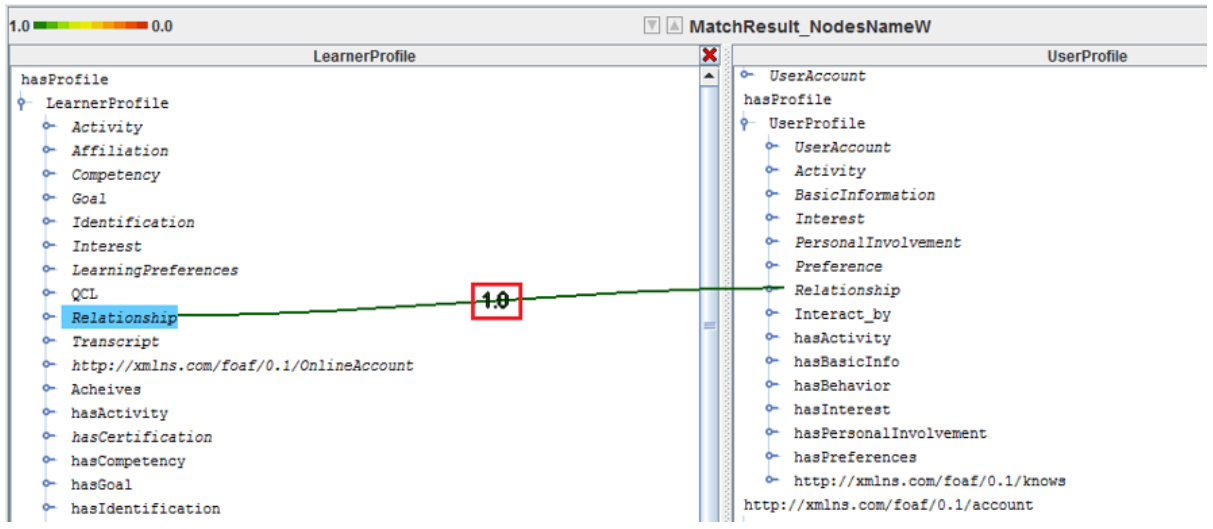

Fig. 12.Match result using NodesPathW matcher

We apply the" NodesPathW" matcher for the process of mapping. Figure 13 represents the mapped ontologies.

Step 3: Ontology merging process using COMA 3.0. Ontology merging is a process of combining two, or more, ontologies into one. Consequently, the resulting ontology stores knowledge from all merged ones.

Merging often utilizes a set of alignments to create deep interconnections between ontologies and, in the end, merge them into one.

We evaluate the quality of the different matchers in order to choose the best for the process of merging. For this purpose, we use the metrics: Precision, Recall and F-measure.

Precision and Recall are commonplace measures in information retrieval. They are based on the comparison of an expected result and the effective result of the evaluated system [45]. F-measure is defined as a weighted combination of $\mathrm{P}$ and $\mathrm{R}$.

Given a reference alignment R: Precision and recall of some alignment $A$ are defined by: 


$$
\mathrm{P}(\mathrm{A}, \mathrm{R})=|\mathrm{R} \cap \mathrm{A} / /| \mathrm{A} \mid \text { and } \mathrm{R}(\mathrm{A}, \mathrm{R})=|\mathrm{R} \cap \mathrm{A}| /|\mathrm{R}|
$$

\begin{tabular}{|c|c|c|}
\hline $1.0=-\quad-2=0.0$ & $\nabla$ Matc & hResult_NodesPathW \\
\hline LearnerProfile & $\bar{x}$ & UserProfile \\
\hline hasProfile & - & of UserAccount \\
\hline Q LearnerProfile & & hasProfile \\
\hline $\begin{array}{l}\text { o- Activity } \\
\text { o. Affiliation }\end{array}$ & & $\begin{array}{l}\text { P. UserProfile } \\
\text { a UserAccount }\end{array}$ \\
\hline $\begin{array}{l}\text { o- Affiliation } \\
\text { o- Competency }\end{array}$ & & $-\infty$ Activity \\
\hline $\begin{array}{l}\text { of Competency } \\
\text { of Goal }\end{array}$ & & $\Longrightarrow$ BasicInformation \\
\hline - Identification & & $\rightarrow$ Interest \\
\hline of Interest & & a. Personalinnol verent \\
\hline a- LearningPreferences & & o- Preference \\
\hline $\begin{array}{l}\text { of QCI } \\
\text { of Relationship }\end{array}$ & & $\rightarrow$ Relationship \\
\hline $\begin{array}{l}\text { of Relationship- } \\
\text { of Transcript }\end{array}$ & & $\begin{array}{l}\circ \text { Interact_by } \\
\infty \text { hasActivity }\end{array}$ \\
\hline o. http://xm1ns.com/foaf/0.1/Onlineaccount & & $\begin{array}{l}\text { hasActivity } \\
\text { o hasBasicInfo }\end{array}$ \\
\hline of Acheives & & o hasBehavior \\
\hline o. hasActivity - & & $\rightarrow$ hasInterest \\
\hline o. hascertification & & of hasPersonalinvolvement \\
\hline $\begin{array}{l}\text { o- hasCompetency } \\
\text { o. hasGoal }\end{array}$ & & $\begin{array}{l}\text { hasPreferences } \\
\text { http://xmlns.com/foaf/o }\end{array}$ \\
\hline o. hasIdentification - & & foaf $/ 0.1$ account \\
\hline of hasInterest-_- & & $\begin{array}{l}\text { o- Useraccount } \\
\text { last_activity_date : rdfs:Literal }\end{array}$ \\
\hline $\begin{array}{l}\text { of hasticence } \\
\text { of hasPreftanguage }\end{array}$ & & $\begin{array}{l}\text { last_activity_date : rdfs:Literal } \\
\text { last_reply_date : rdfs:Literal }\end{array}$ \\
\hline o hasPrefLarningMaterial & & num_Likes : xsd:nonlegativeInteger \\
\hline of hasPrefLearningstyles & & num_comments : xsd:nonlegativeInteger \\
\hline $\begin{array}{l}\text { o haspreferences } \\
\text { a hasQualification }\end{array}$ & - & $\begin{array}{l}\text { num_shares : xsd:nonNegativeInteger } \\
\text { num_views : xsd:nonlegativeInteger }\end{array}$ \\
\hline
\end{tabular}

Fig. 13.Ontology mapping using "NodesPathW" matcher

Figure 14 points out the evaluation result of the three metrics. The merge result of "NodesPathW" and "NodesNamesW" has the highest scores of precision, recall and Fmeasure.

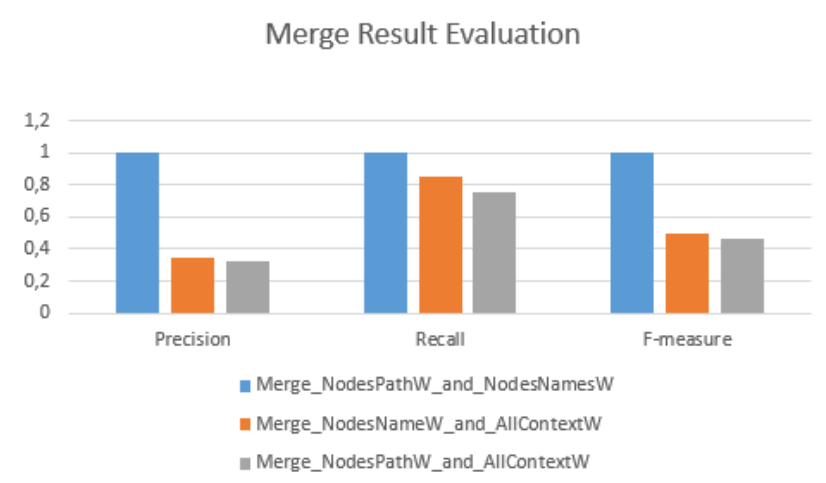

Fig. 14.Evaluation Result of different combination between the match results

Based on the above evaluation, we merge the match result of both "NodesPathW" matcher and "NodesNameW" matcher. Figure 15 represents the result of the merge. 


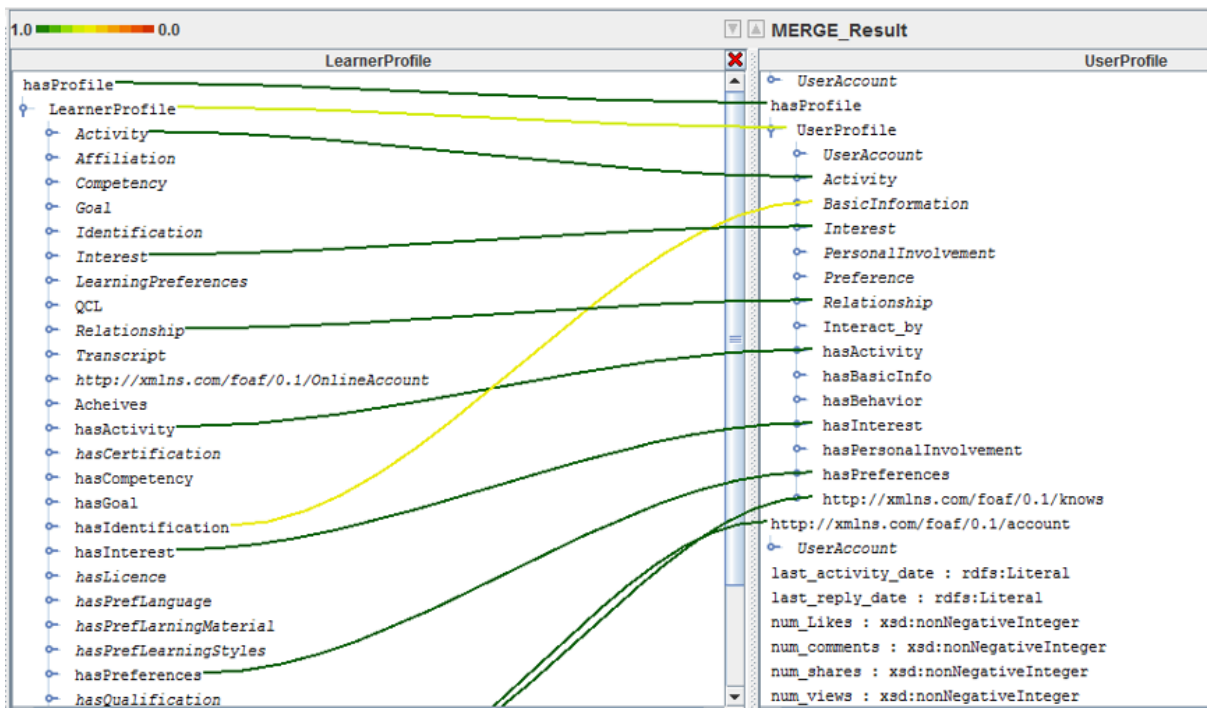

Fig. 15.Merge Result of the mapped ontologies

\section{Conclusion and future work}

The paper proposes an approach to construct a social profile for MOOCs based on the learner profile in social media using ontologies. The aim is to improve the representation of the learner profile based on many useful information and characteristics generated from his interaction and participation in social media.

The main idea of our work, is to provide the learner with the courses that match the best his interest and preferences, which will help him be more engaged and motivated. The construction of the social profile is achieved by incorporating well known standards and ontologies such as IMS-LIP standard, FOAF and SIOC ontology as well as the major concepts that describes the best a user profile in social media. We rely also on ontology mapping and merging technique to generate the global ontology that represents our social profile ontology.

As future work, we intend to apply our model in an existing e-learning system in order to evaluate the impact of the ontology on the drop-out rate. We will instantiate the ontology with real data from both social media and MOOCs. We aim also to classify learners based on their profiles using machine learning techniques for the purpose of collaborative learning and resource recommendation.

\section{$5 \quad$ References}

[1] A. Sharif et B. Magrill, « Discussion Forums in MOOCs », Int. J. Learn. Teach. Educ. Res., vol. 12, no 1, juill. 2015. Available: http://www.ijlter.org/index.php/ijlter/article/view/368

[2] E. O. Burgess, « Attrition and Dropouts in the E-learning Environment: Improving Student Success and Retention », 2017. (Doctoral dissertation, Northcentral University). Available: 
Paper-A Social Profile Ontology to Enhance Learner Experience in MOOCs

https://www.proquest.com/openview/8cd409a87b4b84c522f281c8cfd6418f/1?pq-origsite $=$ gscholar\&cbl $=18750$

[3] H. Aldowah, H. Al-Samarraie, A. I. Alzahrani, et N. Alalwan, « Factors affecting student dropout in MOOCs: a cause and effect decision-making model », J. Comput. High. Educ., p. 1- 26, 2019. https://doi.org/10.1007/s12528-019-09241-y

[4] J. C. Richardson, Y. Maeda, J. Lv, et S. Caskurlu, « Social presence in relation to students' satisfaction and learning in the online environment: A meta-analysis », Comput. Hum. Behav., vol. 71, p. 402- 417, juin 2017. https://doi.org/10.1016/j.chb.2017.02.001

[5] N. Luo, M. Zhang, et D. Qi, « Effects of different interactions on students' sense of community in e-learning environment », Comput. Educ., vol. 115, p. 153-160, 2017. https://doi.org/10.1016/i.compedu.2017.08.006

[6] H. Zankadi, I. Hilal and A. Idrissi, "Designing a Middleware course for a real time interactive learning in Social Learning Environment," 2019 1st International Conference on Smart Systems and Data Science (ICSSD), 2019, pp. 1-5. https://doi.org/10.1109/ICSSD47982. $\underline{2019.9002672}$

[7] C. Greenhow et E. Askari, «Learning and teaching with social network sites: A decade of research in K-12 related education », Educ. Inf. Technol., vol. 22, no 2, p. 623- 645, 2017. https://doi.org/10.1007/s10639-015-9446-9

[8] A. J. Gray, Constructivist teaching and learning. Saskatchewan School Trustees Association, 1997. Available: https://saskschoolboards.ca/wp-content/uploads/97-07.htm

[9] S. Manca et M. Ranieri, «Facebook and the others. Potentials and obstacles of Social Media for teaching in higher education », Comput. Educ., vol. 95, p. 216-230, avr. 2016, https://doi.org/10.1016/j.compedu.2016.01.012

[10] H. Zankadi, I. Hilal, N. Daoudi and A. Idrissi, "Facebook and MOOCs: a Comparative Analysis for a Collaborative Learning," 2018 6th International Conference on Multimedia Computing and Systems (ICMCS), 2018, pp. 1-7. https://doi.org/10.1109/ICMCS.2018.8525493

[11] S. Staab et R. Studer, Handbook on ontologies. Springer Science \& Business Media, 2010. https://doi.org/10.1007/978-3-540-92673-3

[12] C. Calero, F. Ruiz, et M. Piattini, Ontologies for software engineering and software technology. Springer Science \& Business Media, 2006. https://doi.org/10.1007/3-540-34518-3

[13] L. Akharraz, A. El Mezouary, et Z. Mahani, «LMOnto: an ontology-based learner model for technology enhanced learning systems », 2018, p. 137-142. https://doi.org/10. 1007/978-3-030-11914-0_15

[14] A. Ouatiq, K. El, K. Mansouri, et M. Qbadou, «Towards an Ontological Learner's Modeling During and After the COVID-19 Pandemic », Int. J. Adv. Comput. Sci. Appl., vol. 12, no 2, 2021. https://doi.org/10.14569/IJACSA.2021.0120237

[15] O. Zine, A. Derouich, et A. Talbi, «IMS Compliant Ontological Learner Model for Adaptive E-Learning Environments », Int. J. Emerg. Technol. Learn. IJET, vol. 14, no 16, p. 97, août 2019. https://doi.org/10.3991/ijet.v14i16.10682

[16] N. Nehiri et N. Aknin, « A Proposed Learner's Data Model: Integrating Informal Learning and Enhancing Personalization and Interoperability », Int. J. Emerg. Technol. Learn. IJET, vol. 16, no 08, p. 173, avr. 2021. https://doi.org/10.3991/ijet.v16i08.19833

[17] S. Missaoui et A. Maalel, «Student's profile modeling in an adaptive gamified learning environment », Educ. Inf. Technol., p. 1- 15, 2021. https://doi.org/10.1007/s10639-021$\underline{10628-7}$

[18] S. Bennani, A. Maalel, et H. B. Ghezala, « AGE-Learn: Ontology-based representation of personalized gamification in E-learning », Procedia Comput. Sci., vol. 176, p. 1005- 1014, 2020. https://doi.org/10.1016/j.procs.2020.09.096

[19] O. EL AISSAOUI et L. OUGHDIR, «A learning style-based Ontology Matching to enhance learning resources recommendation », 2020, p. 1- 7. https://doi.org/10.1109/IRASET $\underline{48871.2020 .9092142}$ 
[20] S. Bourekkache, O. Kazar, M. Abik, S. Tigane, et L. Kahloul, « Ontology based approach for representing the learner profile and learning styles », 2019, p. 1- 6. https://doi.org /10.1109/ICDS47004.2019.8942276

[21] V. Luna, R. Quintero, M. Torres, M. Moreno-Ibarra, G. Guzmán, et I. Escamilla, « An ontology-based approach for representing the interaction process between user profile and its context for collaborative learning environments », Comput. Hum. Behav., vol. 51, p. 1387- 1394, oct. 2015. https://doi.org/10.1016/j.chb.2014.10.004

[22] F. Grivokostopoulou, I. Perikos, M. Paraskevas, et I. Hatzilygeroudis, « An ontology-based approach for user modelling and personalization in e-learning systems », 2019, p. 1- 6. https://doi.org/10.1109/ICIS46139.2019.8940269

[23] B. Sateli, F. Löffler, B. König-Ries, et R. Witte, «ScholarLens: extracting competences from research publications for the automatic generation of semantic user profiles », PeerJ Comput. Sci., vol. 3, p. e121, juill. 2017. https://doi.org/10.7717/peerj-cs.121

[24] J. Chicaiza, N. Piedra, J. Lopez-Vargas, et E. Tovar-Caro, « A user profile definition in context of recommendation of open educational resources. An approach based on linked open vocabularies », in Frontiers in Education Conference (FIE), 2015 IEEE, 2015, p. 1- 7. https://doi.org/10.1109/FIE.2015.7344314

[25] H. Yago, J. Clemente, D. Rodriguez, et P. Fernandez-de-Cordoba, « ON-SMMILE: Ontology Network-based Student Model for MultIple Learning Environments », Data Knowl. Eng., vol. 115, p. 48- 67, mai 2018. https://doi.org/10.1016/j.datak.2018.02.002

[26] A. Kourtiche, S. mohamed Benslimane, et S. B. Hacene, « OUPIP: Ontology Based User Profile for Impairment Person in Dynamic Situation Aware Social Networks », Int. J. Knowl.-Based Organ. IJKBO, vol. 10, no 2, p. 12- 34, 2020. https://doi.org/10.4018 /IJKBO.2020040102

[27] P. Penas, R. del Hoyo, J. Vea-Murguia, C. Gonzalez, et S. Mayo, « Collective Knowledge Ontology User Profiling for Twitter -- Automatic User Profiling », in 2013 IEEE/WIC/ACM International Joint Conferences on Web Intelligence (WI) and Intelligent Agent Technologies (IAT), Atlanta, GA, USA, nov. 2013, p. 439-444. https://doi.org/10.1109/WIIAT.2013.62

[28] M. A. Musen, « The protégé project: a look back and a look forward », AI Matters, vol. 1, no 4, p. 4- 12, 2015. https://doi.org/10.1145/2757001.2757003

[29] L. Oubahssi et M. Grandbastien, « From learner information packages to student models: Which continuum? », 2006, p. 288- 297. https://doi.org/10.1007/11774303_29

[30] M. Graves, A. Constabaris, et D. Brickley, « Foaf: Connecting people on the semantic web », Cat. Classif. Q., vol. 43, no 3-4, p. 191-202, 2007. https://doi.org/10.1300/J104 $\mathrm{v} 43 \mathrm{n} 03 \quad 10$

[31] R. A. Howard, C. A. Carver, et W. D. Lane, «Felder's learning styles, Bloom's taxonomy, and the Kolb learning cycle: tying it all together in the CS2 course », 1996, p. 227- 231. https://doi.org/10.1145/236452.236545

[32] J. G. Breslin, S. Decker, A. Harth, et U. Bojars, « SIOC: an approach to connect web-based communities », Int. J. Web Based Communities, vol. 2, no 2, p. 133-142, 2006. https://doi.org/10.1504/IJWBC.2006.010305

[33] K. Ramar et G. Gurunathan, « Technical review on ontology mapping techniques », Asian J. Inf. Technol., vol. 15, no 4, p. 676- 688, 2016. Available: http://medwelljournals.com/abstract/?doi=ajit.2016.676.688

[34] H.-H. Do et E. Rahm, « COMA — a system for flexible combination of schema matching approaches », in VLDB'02: Proceedings of the 28th International Conference on Very Large Databases, 2002, p. 610- 621. https://doi.org/10.1016/B978-155860869-6/50060-3

[35] O. Verhodubs et J. Grundspenkis, « Ontology Merging in the Context of a Semantic Web Expert System », in Knowledge Engineering and the Semantic Web, Berlin, Heidelberg, 2013, p. 191 - 201. https://doi.org/10.1007/978-3-642-41360-5 15 
[36] M. Fernández-López, A. Gómez-Pérez, et N. Juristo, « Methontology: from ontological art towards ontological engineering. 1997 », 2017, p. 33-40. Available: https://oa.upm. es/5484/

[37] L. P. Yulianti et K. Surendro, « Ontology Model for Indigenous Knowledge », in 2018 International Conference on Information Technology Systems and Innovation (ICITSI), 2018, p. 231 - 236. https://doi.org/10.1109/ICITSI.2018.8695925

[38] A. Benabdallah, M. A. Abderrahim, et M. E.-A. Abderrahim, « Extraction of terms and semantic relationships from Arabic texts for automatic construction of an ontology », Int. J. Speech Technol., vol. 20, no 2, p. 289- 296, 2017. https://doi.org/10.1007/s10772-0179405-5

[39] O. Corcho, M. Fernández-López, A. Gómez-Pérez, et A. López-Cima, « Building legal ontologies with METHONTOLOGY and WebODE », in Law and the semantic web, Springer, 2005, p. 142- 157. https://doi.org/10.1007/978-3-540-32253-5_9

[40] A. Farquhar, R. Fikes, et J. Rice, « The ontolingua server: A tool for collaborative ontology construction », Int. J. Hum.-Comput. Stud., vol. 46, no 6, p. 707- 727, 1997. https://doi.org/ 10.1006/ijhc.1996.0121

[41] O. Corcho, M. Fernández-López, et A. Gómez-Pérez, «Ontological engineering: principles, methods, tools and languages », in Ontologies for software engineering and software technology, Springer, 2006, p. 1- 48. https://doi.org/10.1007/3-540-34518-3_1

[42] T. R. Gruber, « Toward principles for the design of ontologies used for knowledge sharing? », Int. J. Hum.-Comput. Stud., vol. 43, no 5- 6, p. 907-928, 1995. https://doi.org/10. 1006/ijhc.1995.1081

[43] A. Gómez-Pérez, M. Fernández-López, et O. Corcho, Ontological engineering: with examples from the areas of knowledge management, e-commerce and the Semantic Web / Asunción Gómez-Pérez, Mariano Fernández-López, and Oscar Corcho. London; New York: Springer, 2004.

[44] W. Li et al., Éd., Internet and Distributed Computing Systems, vol. 9864. Cham: Springer International Publishing, 2016.

[45] J. Makhoul, F. Kubala, R. Schwartz, et R. Weischedel, « Performance measures for information extraction », 1999, p. 249- 252. Available: http://citeseerx.ist.psu.edu/viewdoc/sum$\underline{\text { mary?doi }=10.1 \cdot 1 \cdot 27.4637}$

\section{Authors}

Hajar zankadi, is a PhD candidate within the IPSS team, at Mohammed V university, faculty of sciences, computer science department, Rabat, Morocco.

Imane Hilal, is a professor at the information science school (ESI), Rabat, Morocco (email: ihilal@esi.ac.ma).

Abdellah Idrissi, is a professor within the IPSS team, at Mohammed V university, faculty of sciences, Rabat, Morocco (email: idriab@gmail.com).

Najima Daoudi, is a professor at the information science school (ESI), Rabat, Morocco (email: ndaoudi@esi.ac.ma).

Article submitted 2021-10-07. Resubmitted 2021-11-13. Final acceptance 2021-11-15. Final version published as submitted by the authors. 